\title{
Stages of change towards physical activity in a nationally representative sample in the European Union
}

\author{
John M Kearney ${ }^{1}$, Cees de Graaf ${ }^{2}$, Soren Damkjaer ${ }^{3}$ and Lars Magnus Engstrom ${ }^{4}$ \\ ${ }^{1}$ Institute of European Food Studies, Trinity College, Dublin 2, Ireland: ${ }^{2}$ Division of Human Nutrition and \\ Epidemiology, Wageningen Agricultural University, PO Box 8129/6700 EV Wageningen, the Netherlands: \\ ${ }^{3}$ Centre of Sport Science, University of Copenhagen, Jagtvej 155 B, DK-2200 Kobenhavn N, Denmark: \\ ${ }^{4}$ Stockholm Institute of Education, Department of Educational Research, PO Box 34103, \\ S-10026 Stockholm, Sweden
}

\begin{abstract}
Objective: To examine the distribution of the stages of change towards physical activity across Europe and the influence of sociodemographic variables on this distribution.

Design: A cross-sectional study in which quota-controlled, nationally representative samples of approximately 1000 adults from each country completed a face-to-face interview-assisted questionnaire.

Setting: The survey was conducted in the 15 member states of the European Union between March and April 1997.

Subjects: The questionnaire was completed by 15239 subjects (aged 15 years upwards). Data were weighted by population size for each country and by sex, age and regional distribution within each member state.

Results: Twenty-nine per cent of subjects were in the precontemplation stage, while a similar proportion $(30 \%)$ were in the maintenance stage. Ten per cent had been physically active but had relapsed recently. Considerable intercountry variation existed with Scandinavian countries tending to be lower in the precontemplation stage and southern countries tending to be higher (particularly Greece and Portugal). Men and younger subjects with a higher education level were more likely to be in the maintenance stage. Overweight and obese subjects were more likely to be in the precontemplation stage than normal-weight subjects. In terms of barriers to participating in physical activity 'not being the sporty type' was more important for those in precontemplation stages, while 'work/study commitments' was more important for those people in the maintenance stage.

Conclusions: The model of the stages of behavioural change towards physical activity was able to distinguish people according to their level and attitude to physical activity. The considerable intercountry and sociodemographic variation in the distribution of stages of change suggest that targeted programmes aimed at specific subgroups in the population identified using the model may be more effective in promoting physical activity.
\end{abstract}

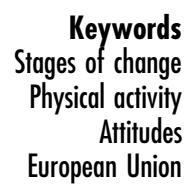

Physical activity is an important component for weight loss programmes to be successful ${ }^{1}$ and is the single best predictor for successfully maintaining that weight loss ${ }^{2}$. In addition to generally low rates of participation in exercise at levels recommended for cardiorespiratory fitness and health, research has found that drop-out rates from exercise programmes were $50 \%$ in the first 3-6 months ${ }^{3}$. A lack of understanding of the knowledge and attitudes associated with taking up and maintaining exercise has hindered efforts to develop programmes which are lasting and effective ${ }^{4}$. While most exercise programmes are designed for people who are ready to take action to become more physically active, most people are not in this stage of readiness 5 . Thus, a major contributor to the large dropout rates from exercise programmes may be due to the mismatch between what exercise programmes are designed for (primarily action-oriented programmes) and people's level of readiness to become physically active, as most people are likely to be inactive and have little interest in becoming so ${ }^{6}$.

Recent research on the determinants of, and interventions for, physical activity has been to utilize psychological theory to provide a framework for 
understanding, predicting and changing behaviour ${ }^{7}$. A number of psychological models of decision making have been applied to physical activity to increase the level of maintenance in exercise programmes. Such models as the health belief model and the theory of reasoned action have not been that successful in explaining exercise behaviour. The health belief model assumes that individuals who feel more susceptible to disease will be motivated to become physically active by their belief that such exercise will result in benefits that outweigh the cost. However, it has been shown that unhealthy people are even less likely to exercise in spite of feeling that physical activity would be beneficial in prevention or treating disease $^{8}$. The theory of reasoned action suggests that attitudes towards physical activity along with social norms can predict behaviour. However, in descriptive studies of this model it was found that the theory of reasoned action predicted only one-third of exercise intentions, of which only $25 \%$ actually translated into long-term action ${ }^{6}$.

In contrast, interventions using behaviour modification have been more successful in increasing maintenance of physical activity from 50\% to $60 \%{ }^{6}$. Successful behavioural change depends to some degree on the willingness of individuals to make the necessary changes. The transtheoretical model of stages of change suggests that when people attempt to make changes in their behaviour they move through stages of precontemplation, contemplation, decision, action and maintenance in a sequential though often cyclical and not necessarily linear manner ${ }^{9}$. Use of such a model has been successfully applied to intervention programmes aimed at cessation of addictive behaviours, such as drugs and smoking, which are specifically geared to individuals at a particular stage (precontemplation or contemplation) and aimed at moving them into action and maintenance ${ }^{10,11}$. It has also been used successfully in specifically designed intervention programmes aimed at the adoption of healthier practices such as eating low-fat diets and increased physical activity ${ }^{9,12,13}$. Existing knowledge on the maintenance of exercise behaviour consists mainly of the benefits and barriers (perceived and real) for taking up exercise and the reasons for dropping out. Little is known about the sociodemographic factors which influence readiness to become active and the factors which could influence outcome in terms of maintaining a physically active lifestyle.

This pan-EU survey is the first of its kind to provide comparable data on the stages of change towards physical activity. The objective of this study was to explore the sociodemographic determinants of the stages of change towards physical activity in the 15 member states of the EU in order to examine how factors such as sex, age, social class, culture and current body mass index (BMI) influence which stage one is in. Such information may help those involved in promoting physical activity to develop more focused and specific intervention programmes tailored to the needs of the population of interest, as well as helping in the success of maintaining such programmes.

\section{Methods}

A questionnaire including 12 close-ended questions was developed following a workshop comprising scientists from all member states of the EU along with industry representatives and the Institute of European Food Studies (IEFS). Approximately 1000 adults (15 years old and upwards) were selected from each member state. The sample was larger in Germany $(n=1250)$ and in the UK $(n=1250)$. In Luxembourg, the target sample was 500. Subject selection was quotacontrolled to make samples nationally representative. In total 15239 subjects participated in a face-to-face interview-assisted questionnaire which was conducted as part of 'Eurobus' between March and April 1997. Details of the questionnaire design, sample selection and administration have been described elsewhere in this volume ${ }^{14}$. The stages of change towards physical activity were assessed by a question designed to assign people to one of these stages adapted from Godin and Shephard ${ }^{15}$. They could also be assigned to a sixth category called 'relapse' in which subjects had been physically active in the past but who had not maintained such changes. The question consisted of seven mutually exclusive options, according to which subjects were assigned to one of the six stages of change groups as follows.

- I am currently not very physcially active and I do not intend becoming more physically active in the next 6 months (precontemplation group).

- I am currently not very physically active but I am thinking about increasing my activity in the next month (contemplation group).

- I am currently not very physically active but I am determined to increase my activity in the next month (decision group).

- I am currently quite physically active, but I have only begun to be so in the last 6 months (action group).

- I am currently quite physically active and I have been so for longer than 6 months (maintenance group).

- I used to be quite physically active a year ago, but in the last few months I have been less active (relapse group).

- Do not know.

For some of the analyses, mean stage of change scores were calculated as an index of the stage 
distribution as used in an earlier study ${ }^{16}$. Each of the stages of change groups were given a score. The scoring system was as follows:

$1=$ precontemplation;

$2=$ contemplation;

$3=$ decision;

$4=$ action;

$5=$ maintenance.

As no interpretable value could be given to the relapse group it was excluded from the calculation of mean scores. Some cross-question analyses were conducted to examine the relationship between stages of change and attitudes to physical activity including the reasons for and barriers to participating in physical activity.

Due to the large sample size, even small differences in the order of $2-3 \%$ between groups were highly statistically significant. The main aim of this study was to examine the influence of sociocultural factors on stages of change and whether attitudes towards physical activity and the motivating factors and barriers to participating in physical activity differ according to stage of change. We were interested in sizeable differences (in the order of 10\%) which would be of use in the development of tailormade intervention programmes. Such practical differences rather than statistical differences will, therefore, be highlighted in this discussion.

\section{Results}

Table 1 outlines the distribution of subjects in the 15 member states across the six stages towards physical activity. On average, almost one-third are in the precontemplation stage and one-third are in the maintenance stage. Data for the EU sample have been weighted for population size while data for individual countries have been weighted to make them nationally representative. A disproportionate number of the Italian sample (33\%) did not select any of the six options in this question, so in addition to the response 'Do not know', a response 'None of the above' was made for the Italian sample. This group in the Italian sample has been excluded from all analyses for Italy and the EU as a whole. Large between-country differences were evident with three-fold differences in the precontemplation stage (Ireland and Italy 15\% versus Greece and Portugal 46\%) and in the maintenance stage (Greece $14 \%$ versus Ireland 47\%). Comparing the mean stage of change score between countries, Ireland and the UK had the highest scores while Greece and Portugal had the lowest reflecting the high proportion of subjects in precontemplation, almost half, in Greece and Portugal.

On average $10 \%$ of EU respondents were in the relapse stage; however, as in the other stages, there was considerable intercountry variation with Finland having the lowest (6\%) and Sweden the highest (15\%) percentage of subjects in relapse. A higher proportion of Swedish respondents in relapse, compared to the other member states, was also found in regard to stages of dietary change in an earlier study ${ }^{16}$. Relapse prevention is of major concern and a genuine challenge to those working in the field of behavioural modification ${ }^{17}$.

Stages of change towards physical activity were also examined by sociodemographics (Table 2). Males were less likely to be in precontemplation and more likely to have been active for over 6 months compared to females. An even more important distinction in the stage of change distribution is seen across age with the proportion of respondents in the precontemplation stage rising with increasing age. A similar level of decline in maintenance is seen with increasing age

Table 1 Percentage of subjects in each member state at the various stages of change towards physical activity

\begin{tabular}{|c|c|c|c|c|c|c|c|c|}
\hline Country & No. & Mean stage score* & Precontemplation & Contemplation & Decision & Action & Maintenance & Relapse \\
\hline Austria & 931 & 3.11 & 23 & 13 & 15 & 4 & 32 & 7 \\
\hline Belgium & 982 & 2.58 & 44 & 8 & 4 & 3 & 28 & 8 \\
\hline Denmark & 1147 & 3.21 & 25 & 12 & 10 & 5 & 38 & 11 \\
\hline Finland & 979 & 2.98 & 18 & 22 & 23 & 5 & 25 & 6 \\
\hline France & 1003 & 2.65 & 38 & 13 & 6 & 4 & 27 & 10 \\
\hline Germany & 1159 & 2.72 & 32 & 15 & 9 & 4 & 26 & 8 \\
\hline Greece & 1011 & 2.09 & 46 & 11 & 6 & 3 & 14 & 13 \\
\hline Ireland & 1001 & 3.69 & 15 & 11 & 8 & 7 & 47 & 10 \\
\hline Italy & 673 & 3.53 & 15 & 12 & 8 & 6 & 39 & 14 \\
\hline Luxembourg & 518 & 2.87 & 30 & 13 & 7 & 5 & 28 & 9 \\
\hline Netherlands & 1010 & 3.16 & 26 & 12 & 7 & 6 & 37 & 9 \\
\hline Portugal & 1007 & 2.29 & 46 & 12 & 4 & 2 & 21 & 10 \\
\hline Spain & 1000 & 2.76 & 33 & 12 & 9 & 7 & 25 & 12 \\
\hline Sweden & 1001 & 3.14 & 20 & 20 & 15 & 4 & 35 & 15 \\
\hline UK & 1490 & 3.44 & 18 & 11 & 9 & 7 & 41 & 13 \\
\hline EU average† & 14912 & 3.44 & 29 & 13 & 8 & 5 & 30 & 10 \\
\hline
\end{tabular}

${ }^{*}$ Mean stage score calculated as: precontemplation $=1$, contemplation $=2$, decision $=3$, action $=4$, maintenance $=5$.

† Weighted according to population size. 
Table 2 Percentage of EU subjects at various stages of change towards physical activity*, classified by demographics (sex, age, education level and marital status)

\begin{tabular}{|c|c|c|c|c|c|c|c|c|}
\hline & No. & Mean stage score & Precontemplation & Contemplation & Decision & Action & Maintenance & Relapse \\
\hline \multicolumn{9}{|l|}{ Sex } \\
\hline Males & 7011 & 3.17 & 26 & 11 & 7 & 4 & 36 & 11 \\
\hline Females & 7894 & 2.74 & 32 & 14 & 9 & 6 & 25 & 10 \\
\hline \multicolumn{9}{|l|}{ Age (years) } \\
\hline $15-24$ & 2595 & 3.46 & 15 & 14 & 11 & 9 & 37 & 11 \\
\hline $25-34$ & 3024 & 2.97 & 25 & 17 & 9 & 5 & 30 & 10 \\
\hline $35-44$ & 2856 & 2.97 & 28 & 14 & 9 & 3 & 31 & 9 \\
\hline $45-54$ & 2457 & 2.75 & 33 & 13 & 8 & 4 & 27 & 10 \\
\hline $54-65$ & 2110 & 2.78 & 36 & 9 & 6 & 3 & 29 & 9 \\
\hline $65+$ & 1866 & 2.59 & 40 & 5 & 5 & 3 & 25 & 14 \\
\hline \multicolumn{9}{|l|}{ Education level } \\
\hline Primary & 4687 & 2.56 & 39 & 11 & 8 & 4 & 24 & 10 \\
\hline Secondary & 7560 & 3.09 & 25 & 13 & 8 & 5 & 33 & 11 \\
\hline Tertiary & 2629 & 3.19 & 23 & 14 & 9 & 6 & 35 & 10 \\
\hline \multicolumn{9}{|l|}{ Marital status } \\
\hline Single & 4711 & 3.31 & 20 & 13 & 9 & 6 & 37 & 11 \\
\hline Married/cohabiting & 8555 & 2.81 & 32 & 13 & 8 & 4 & 28 & 10 \\
\hline Widowed/divorced & 1639 & 2.55 & 38 & 9 & 7 & 6 & 22 & 12 \\
\hline
\end{tabular}

* The 'do not knows' are not included so percentages do not add up to $100 \%$. † Mean stage score calculated over stages $1-5$.

resulting in the youngest age group (15-24 years) having the highest mean stage of change score (3.46) and the oldest age group (65+ years) having the lowest score (2.59). Indeed subjects in the youngest age group had the highest mean stage of change score of all sociodemographic groups.

An effect of education level was also apparent with subjects having a primary-level education more likely to not be considering becoming active and to be inactive compared to those with a higher level of education. The effect of sex, age and education was less pronounced on the other four stages of change: contemplation, decision, action and relapse. Looking at marital status, single people are half as likely to be in the precontemplation stage compared to those who are widowed or divorced. These results may be directly related to age since single people are more likely to be in the younger age groups and widowed/divorced in the older age groups.

Since the main sociodemographic influences were sex and age and these were most apparent in the precontemplation and maintenance stages, it was decided to examine whether such influences were consistent for the different countries in the EU (Appendix). The effect of age varied between countries in the proportion of subjects in the precontemplation stage. The greatest contrast was seen in Denmark (15-34-year-old males 7\%, over 55-year-old males $39 \%$ ) and Portugal (15-34-year old males 22\%, over 55 -year-old males 63\%) while in other countries little or no effect was evident among males of different ages in the precontemplation stage (Luxembourg and the Netherlands). This lack of an effect of age for males in some countries is not apparent for females where in all 15 member states there was a rise (often two-fold) in the proportion of subjects in precontemplation between the youngest and oldest age groups.

Similar to the precontemplation stage, the effect of age is stronger than sex on the maintenance stage in the different member states. The level of decline with age among males varies widely from no change among Irish males across age to an almost four-fold decline among Portuguese males from the youngest to the oldest age group. Thus, an effect of age, sex and country was evident such that there is a 12-fold difference among those who are active (and have been for over 6 months) between 15-34-year-old Irish males (50\%) and over 55-year-old Greek females (4\%).

Table 3 shows the distribution of stages of change according to body-weight status. This was determined by BMI and four categories were defined: underweight (BMI $\leqslant 19.99 \mathrm{~kg} \mathrm{~m}^{-2}$ ); normal weight (BMI 20.0-24.99 $\mathrm{kg} \mathrm{m}^{-2}$ ); overweight (BMI 25$29.99 \mathrm{~kg} \mathrm{~m}^{-2}$ ) and obese (BMI $\geqslant 30 \mathrm{~kg} \mathrm{~m}^{-2}$ ). With increasing BMI category there is an increasing proportion of subjects in the precontemplation stage and a corresponding decrease in the proportion for subjects who are active (in maintenance stage). Just $16 \%$ of those who are obese are in maintenance while $39 \%$ of them are in precontemplation. In contrast, in the normal weight category the highest proportion of subjects are in the maintenance stage. There was no effect of BMI category on the distribution of subjects in the contemplation, decision and action stages.

Table 4 shows the percentage of subjects either strongly agreeing or tending to agree with the statements 'I do not need to do more physical activity than I already do' and 'most of my friends take plenty 
Table 3 Percentage of EU subjects at various stages of change towards physical activity classified by BMI category

\begin{tabular}{|c|c|c|c|c|c|c|c|c|}
\hline BMl category $\left(\mathrm{kg} \mathrm{m}^{-2}\right)$ & No. & Mean stage score* & Precontemplation & Contemplation & Decision & Action & Maintenance & Relapse \\
\hline $\begin{array}{l}\text { Underweight } \\
(\leqslant 19.99)\end{array}$ & 1627 & 2.52 & 26 & 13 & 7 & 6 & 31 & 13 \\
\hline $\begin{array}{l}\text { Normal weight } \\
(20.0-24.99)\end{array}$ & 7199 & 2.77 & 25 & 12 & 8 & 6 & 36 & 10 \\
\hline $\begin{array}{l}\text { Overweight } \\
(25.0-29.99)\end{array}$ & 4499 & 2.32 & 33 & 13 & 9 & 4 & 26 & 10 \\
\hline $\begin{array}{l}\text { Obese } \\
(\geqslant 30.00)\end{array}$ & 1364 & 1.91 & 39 & 13 & 10 & 4 & 16 & 13 \\
\hline
\end{tabular}

* Mean stage score calculated over stages 1-5.

Table 4 Percentage of EU subjects who agree strongly or tend to agree with the statements 'I do not need to do more physical activity/ exercise than I already do' and 'most of my friends take plenty of physical activity' classified by stages of change

\begin{tabular}{|c|c|c|c|c|c|c|c|}
\hline Statement & No. & Precontemplation & Contemplation & Decision & Action & Maintenance & Relapse \\
\hline \multicolumn{8}{|c|}{$\begin{array}{l}\text { 'I do not need to do more physical } \\
\text { activity than I already do' }\end{array}$} \\
\hline Strongly agree & 3043 & 19 & 8 & 7 & 18 & 30 & 14 \\
\hline Tend to agree & 3990 & 30 & 18 & 18 & 33 & 35 & 24 \\
\hline \multicolumn{8}{|c|}{$\begin{array}{l}\text { 'Most of my friends take plenty of } \\
\text { physical activity' }\end{array}$} \\
\hline Strongly agree & 1623 & 6 & 7 & 8 & 13 & 15 & 7 \\
\hline Tend to agree & 4391 & 22 & 29 & 33 & 32 & 34 & 28 \\
\hline
\end{tabular}

of physical activity'. More subjects in the maintenance stage either strongly agree or tend to agree that they do not need to do more physical activity than they already do with 65\% agreeing, compared to the other stages. In spite of not being very active and not planning to become so in the next 6 months almost half of those in the precontemplation stage agree either strongly or tend to agree that they do not need to do more. There appears to be a relationship between being active oneself and having most of one's friends active, with the finding that almost half of those in the maintenance stage either strongly or tend to agree that most of their friends take plenty of physical activity while only just over a quarter of those in precontemplation agree with this statement.

Attitudes towards physical activity, body weight and health were examined between those in maintenance and precontemplation stages of change (Table 5). Food, smoking and stress were the most frequently cited important influences on health among both groups. Indeed, physical activity was the only influence to differ markedly between both groups, being selected by a quarter of those in the maintenance stage and by just one-tenth of those in the precontemplation stage. Tables 6 and 7 show the main perceived motivating factors and barriers to participating in physical activity according to stage of change. 'For good health' was the perceived motivating factor selected most frequently by subjects in all stages, though the proportion was considerably lower in the precontemplation stage compared to the others. The selection of such motivating factors as 'for fun' and 'to get fit' were also considerably lower when compared to other stages. In contrast the proportion in precontemplation selecting 'do not participate' (23\%) was far more than the proportion in any of the other stages (7\% or less). 'To lose weight' as a motivating factor was selected more frequently by subjects in contemplation, decision and action. The most frequently selected barrier among those in precontemplation was 'not the sporty type' (42\%). This perceived barrier was only selected by $9 \%$ of those in maintenance. For them the most frequently selected barrier was 'work/study commitments'. The more frequent selection of the barriers 'health not good enough', 'no energy' and 'too old' by those in the precontemplation stage compared to those in the action and maintenance stages is probably a reflection of their older age profile.

Table 5 Percentage of EU subjects citing different factors as the most important influences on health classified by stages of change towards physical activity

\begin{tabular}{lcc}
\hline Health factors & Precontemplation & Maintenance \\
\hline Food & 42 & 39 \\
Body weight & 14 & 11 \\
Smoking & 39 & 40 \\
Environment & 17 & 15 \\
Physical activity/exercise & 11 & 25 \\
Alcohol intake & 22 & 18 \\
Stress & 30 & 31 \\
Genetics & 10 & 9 \\
Support of the family & 6 & 5 \\
\hline
\end{tabular}


Table 6 Percentage of EU subjects citing different perceived motivating factors for participating in physical activity/exercise classified by stages of change

\begin{tabular}{|c|c|c|c|c|c|c|c|}
\hline Motivating factor & All & Precontemplation & Contemplation & Decision & Action & Maintenance & Relapse \\
\hline To relieve tension & 29 & 22 & 31 & 34 & 31 & 33 & 32 \\
\hline To be out of doors & 20 & 21 & 18 & 17 & 18 & 20 & 23 \\
\hline For good health & 42 & 37 & 49 & 47 & 50 & 44 & 40 \\
\hline To socialize & 14 & 11 & 12 & 12 & 17 & 17 & 16 \\
\hline To lose weight & 13 & 11 & 18 & 20 & 16 & 10 & 13 \\
\hline For fun & 31 & 21 & 33 & 37 & 38 & 36 & 36 \\
\hline To get fit & 31 & 21 & 33 & 37 & 38 & 36 & 36 \\
\hline Do not participate & 10 & 23 & 7 & 3 & $<1$ & 2 & 6 \\
\hline
\end{tabular}

\section{Discussion}

While the benefits of exercise are well established and recognized, trying to get inactive individuals to start exercising and active individuals to keep exercising remains the challenge in a culture that is becoming increasingly automated ${ }^{18}$. The need to survey what stage of change towards physical activity populations are in has been emphasized by Prochaska and Marcus? Most behavioural change research and behaviour change interventions are designed for people in the decision stage (i.e. they are prepared for action). However, available research suggests that only a very small percentage of people at risk (i.e. those who are inactive) are in the decision stage ${ }^{9}$, most of them being in the precontemplation stage. Specific action directed towards these two stages is needed, for example helping individuals to think about changing and becoming physically active is the major challenge for those in the precontemplation stage. While for those considering becoming physically active helping them to take action is the task. In an attempt to be more successful with interventions and promotion of physical activity it is important to recognize that people differ in their motivation to become active and to tailor the counselling message according to the individual's readiness for change ${ }^{18}$. For this, it is necessary to examine the sociocultural determinants of behavioural change regarding physical activity.

To determine people's behavioural stage regarding physical activity, respondents were asked to select one of seven options in a question which related one's current activity level to one's attitude to physical activity. The question was modified from a questionnaire used by Godin and Shephard ${ }^{15}$. Answering any one of the first six options placed subjects into one of the six stages of change towards physical activity. The last option was for those who did not know which stage they were in. Data from this question in the survey provide a distribution of the stage of behavioural change towards physical activity in the EU population and also among different sociodemographic groups and in the 15 countries of the EU.

Results from this study show that almost one-third of the EU population are not considering becoming physically active while almost a further one-third believe themselves to be in the maintenance stage, having been physically active for more than 6 months. Forty-two per cent of the EU sample were in precontemplation and contemplation. This is very similar to results from a cross-sectional study by Marcus and Owen $^{19}$ in which they examined the prevalence of stages of readiness to exercise in a sample of USA workers $(n=1093)$ and Australian workers $(n=801)$. In both of these samples $41 \%$ were in precontemplation and contemplation. Wide geographic variation exists in the distribution of stages of change towards physical activity with a three-fold variation in the precontemplation stage between individual countries (for example Ireland 15\% versus Greece and Portugal

Table 7 Percentage of EU subjects citing different perceived barriers to increasing one's level of physical activity/exercise classified by stages of change

\begin{tabular}{|c|c|c|c|c|c|c|c|}
\hline Motivating factor & All & Precontemplation & Contemplation & Decision & Action & Maintenance & Relapse \\
\hline Not the sporty type & 25 & 42 & 30 & 25 & 16 & 9 & 18 \\
\hline Looking after children/elderly & 11 & 10 & 14 & 13 & 12 & 10 & 14 \\
\hline No one to do it with & 8 & 8 & 11 & 14 & 9 & 5 & 7 \\
\hline Expense & 10 & 8 & 12 & 14 & 15 & 9 & 13 \\
\hline Health not good enough & 11 & 15 & 10 & 9 & 9 & 8 & 15 \\
\hline Work/study commitments & 28 & 22 & 34 & 34 & 33 & 28 & 32 \\
\hline No energy & 11 & 16 & 14 & 15 & 6 & 6 & 11 \\
\hline No facilities & 9 & 8 & 13 & 13 & 11 & 8 & 9 \\
\hline Too old & 10 & 16 & 5 & 7 & 6 & 6 & 12 \\
\hline Other things & 11 & 15 & 14 & 13 & 7 & 7 & 10 \\
\hline No need & 12 & 12 & 5 & 5 & 10 & 18 & 11 \\
\hline
\end{tabular}


46\%). Similar variation was evident in the maintenance stage. This variation between countries was not regionalized in that many neighbouring countries had markedly different distributions, e.g. almost half of the Portuguese respondents claimed to be in the precontemplation stage versus one-third of Spanish respondents. However, there was a tendency for Scandinavian countries to be in a later stage of behavioural change compared to the southern countries. Gender and age appear to be the most influential sociodemographic factors affecting the distribution of subjects in the various stages of change. With increasing age subjects are more likely to be in the precontemplation stage. This agrees with results from earlier studies in which older adults are less likely to be active or in the maintenance stage ${ }^{8}$. Women and subjects with a primary-level education are more likely to be in precontemplation whereas men and those subjects with a third-level education were more likely to be in the maintenance stage. Again, this is consistent with previous studies undertaken in the USA which found that less educated and older adults are more likely to be inactive ${ }^{20}$ and engage in less leisuretime physical activity than the general population ${ }^{21,22}$. Indeed, it is believed that a number of factors that influence participation in physical activity appear to affect women more than men ${ }^{23}$. Life stages or events such as adolescence or becoming a parent have been shown to have a significant impact on women's physical activity participation ${ }^{23}$.

In all countries except Italy respondents did not have a problem selecting one of the available options (the percentage of respondents selecting 'do not know' in the EU was low at 3\% and this was no different to other questions). In Italy, however, a disproportionate number (31\%) were not able to pick one of the options and so a new category of 'none of the above' was assigned to this group (to distinguish them from the group selecting 'do not know'). Analyses at EU and individual country level of the data were run with and without this group in Italy and results did not differ significantly and all conclusions arising from the study remained unchanged. For example, the proportion in precontemplation in the total EU sample was $27 \%$ when the 'not selected' group was included and $29 \%$ excluding the Italian 'not selected' group. Furthermore, the relative proportions of all the stages remained unchanged with the maximum change in the precontemplation group (2\%), a difference which is not statistically significant nor of practical significance. Since there were no appreciable differences in the outcome of results with or without the Italian group the authors decided to exclude them since it was not possible to assign them to any one stage. When looking at the data specific to the Italian sample, while the percentage of all stages increases with the exclusion of the 'not selected' group, the relative proportions in the various stages remains the same, i.e. there are 2-6 times as many in the maintenance stage compared to the precontemplation stage. However, since all of the respondents in the 'not selected' group were nonparticipants (assessed from another question in the survey on participation in various activities during leisure time), they are more likely to be either in the precontemplation, decision or relapse stages. Therefore, the relative proportions in the precontemplation stage in Italy is probably a bit low.

With increasing body weight (BMI category) subjects were more likely to be in the precontemplation stage. Overweight individuals have been shown to be less physically active than normal weight subjects ${ }^{8}$. Exercise programmes involving moderate intensity exercise such as walking may be more suitable for overweight subjects, older subjects and those with a low income, as all of these groups not only participate in less leisure-time physical activity, but also tend to participate less in vigorous activities.

Attitudes towards physical activity as an important influence on health were clearly different between people in the precontemplation and maintenance stages of change. The higher percentage of subjects who are physically active selecting physical activity as an important influence to health, compared to those who are inactive and not even considering becoming active, is similar to results from the Allied Dunbar National Fitness Survey (ADNFS) conducted in the $\mathrm{UK}^{24}$, in which only $47 \%$ of those classed as sedentary perceived that exercise was important to their health compared to $63 \%$ of those involved in vigorous exercise. Differences were also found in the percentage of subjects agreeing with the statement 'I do not need to do more physical activity/exercise than I already do'. Not surprisingly, agreement (those who strongly or tend to agree combined) was highest among those in maintenance (two-thirds) and lowest among those in the contemplation and decision stages (one-quarter), considering that they have thought about or made the decision to become more physically active. What was interesting was the proportion of those in precontemplation (half) who agreed that they do not need to be more physically active. This group of inactive people do not see any need to be physically active or it may be that they feel they already are doing enough. Either way it represents an important barrier for changing behaviour. Such misconception about one's behaviour has been noted in relation to dietary practices ${ }^{25}$, and is known to be a barrier for dietary change ${ }^{26}$. Further qualitative research is needed to explore this misconception about one's behaviour in regard to physical activity in an attempt to overcome such a barrier. In some ways the differences in the level of agreement to the statement 'I do not need to do more physical 
activity/exercise than I already do' may be seen as validating the distribution into the various stages of change in this survey. Further internal validity was evident from the proportion of those in the maintenance stage considering physical activity to be important to health compared to those in precontemplation. By definition, the precontemplation stage comprises people who are uninterested in that specific behaviour, while those in the maintenance stage are much more health conscious and interested in the behaviour ${ }^{10}$.

Another question in the survey sought information on participation in various physical activities in a typical recent week ${ }^{27}$. The percentage of subjects in precontemplation who claimed they did not participate in any activity in a recent week (54\%) was far higher than the proportion of those in maintenance $(6 \%)$ or in the action stage (6\%). Furthermore, the two countries, Portugal and Greece, with the highest level of non-participation in physical activity also had the highest proportion of subjects in the precontemplation stage. Such internal consistency between these questions provides evidence that the transtheoretical model is able to distinguish groups with both differing attitudes and self-reported levels of physical activity. Other studies have examined the validity of the stages of exercise adoption instrument with a wellaccepted activity instrument, the seven day physical activity recall questionnaire ${ }^{28}$ and found that the stage instrument had concurrent validity with the physical activity report questionnaire ${ }^{29}$. Additional studies to examine the model in relation to more objective measures of physical activity are needed.

In addition to the differing attitudes of those in various stages of change the perceived motivation factors and barriers to participating in physical activity also differed, particularly between those in precontemplation and in maintenance. For those who are considering becoming more physically active or who have just recently become physically active, 'to lose weight' is more frequently mentioned than for those in precontemplation or in maintenance. The main perceived barrier cited by those in the precontemplation stage was 'not being the sporty type'. It was considerably more important than such physical barriers as expense or lack of facilities. The idea that one needs to be 'sporty', not too old, healthy and have lots of energy to participate in physical activity is the commonly held belief among those who are not active and have no current intention of becoming so. These, therefore, could either be selected as good excuses to justify why subjects are not active or represent genuine feelings that there is a need to be young, fit and healthy to be able to participate in physical activities. Thus, in programmes to encourage people to be more physically active, not only should account be taken of the transtheoretical model to divide the population into various stages, but a knowledge of the different perceived barriers and motivating factors for participating in physical activity among these stages may be important to ensure more effective intervention. The transtheoretical model has been shown to be most helpful and successful in guiding research in the cessation of addictive behaviours?. Since the process of initiating physical activity could be seen as the cessation of sedentary activity this model should be useful to those involved in the promotion of physical activity.

The results of the present study on the stages of change towards physical activity suggest almost onethird of EU subjects are in precontemplation while a further one-third are in the maintenance stage. Results also show that large variability exists between the member states in the proportion of subjects in each stage. Indeed, differences between countries as well as sociodemographic groups tended to be larger with stages of change towards physical activity than with stages of change with respect to healthy eating ${ }^{16}$. While the effect of education was similar, that of gender and age was different between stages of change towards physical activity and healthy eating. Along with the wide degree of variability in the stages of change within each country due to sociodemographic factors, this indicates the importance of localized campaigns which are specifically targeted to groups in the population classified by stage of behaviour change and sociodemographic profile. Otherwise, promotional efforts at increasing physical activity levels in the population through getting inactive people to start being active, and active people to continue being active may not be as successful as they might be were a tailored approach to behavioural change adopted. Further qualitative research is needed to tease out the reasons and underlying influences as to why people are in the various stages of change towards physical activity.

\section{References}

1 Pavlov KN, Krey S, Steffee WP. Exercise as an adjunct to weight loss and maintenance in moderately obese subjects. Am. J. Clin. Nutr. 1989; 49: 1115-23.

2 Wilfley DE, Brownell KD. Physical activity and diet in weight loss. In: Dishman RK, ed. Advances in Exercise Adberence. Champaign, IL: Human Kinetics, 1994; 351-83.

3 Dishman RK. Compliance/adherence in health related exercise. Health Psychol. 1982; 1: 237-67.

4 Blair SN, Morton E, Leon AS, et al. Physical activity, nutrition and chronic disease. Med. Sci. Sports Exerc. 1996; 28: 33549.

5 Marcus BM, Banspach SW, Léfebvre RC, Rossi JS, Carleton RC, Abrams DB. Using the stages of change model to increase the adoption of physical activity among community participants. Am. J. Health Prom. 1992; 6: 424-9.

6 Dishman RK. Determinants of participation in physical activity. In: Bouchard C, Shephard RJ, Stephens T, Sutton JR, 
McPherson BD, eds. Exercise, Fitness and Health. Champaign, IL: Human Kinetics, 1990; 75-102.

7 Marcus BH. Exercise behaviour and strategies for intervention. Res. Q. Exerc. Sport 1995; 66: 319-23.

8 King AC, Blair SN, Bild DE, et al. Determinants of physical activity and interventions in adults. Med. Sci. Sports Exerc. 1992; 24 (Suppl.); S221-36.

9 Prochaska JO, Marcus BJ. The transtheoretical model-the applications to exercise. In: Dishman RK, ed. Advances in Exercise Adherence. Champaign, IL: Human Kinetics, 1994: 161-80.

10 Prochaska JO, DiClemente CC, Norcross JC. In search of how people change: applications to addictive behaviours. Am. Psychol. 1992; 47: 1102-14.

11 Strecher VJ, Krevter M, Denboer DJ, Kobrin S, Hospers HJ, Skinner CS. The effects of computer-tailored smoking cessation messages in family practice settings. J. Fam. Pract. 1994; 39: 262-70.

12 Brug J, Steenhuis I, VanAssema P, De Vries M. The impact of a computer-tailored nutrition intervention. Prev. Med. 1996; 25: 1-7.

13 Campbell M, De Vellis BM, Strecher VJ, Ammerman AS, De Vellis RF, Saudler RS. Improving dietary behaviour: the effectiveness of tailored messages in primary health settings. Am.J. Pub. Med. 1994; 84: 783-7.

14 Kearney JM, Kearney MJ, McElhone S, Gibney MJ. Methods used to conduct the pan-European Union survey on consumer attitudes to physical activity, body weight and health. Public Health Nutr. 1999; 2: 79-86.

15 Godin G, Shephard RJ. A simple method to assess exercise behaviour in the community. Can. J. Appl. Sports Sci. 1985; 10: $141-6$.

16 De Graaf C, Van der Gaag M, Kafatos A, Lennernas M, Kearney JM. Stages of dietary change among nationallyrepresentative samples of adults in the European Union. Eur. J. Clin. Nutr. 1997; 51: S49-56.

17 Marlatt GA, Gordon JR, eds. Relapse Prevention: Maintenance Strategies in the Treatment of Addictive Behaviours. New York: Guilford Press, 1985.

18 Marcus BH, Forsyth LH. The challenge of behavioural change. Med. Health RI 1997; 80: 300-2.
19 Marcus BH, Owen N. Motivational readiness, self-efficacy and decision-making for exercise. J. Appl. Soc. Psychol. 1992; 22: 3-16

20 King AC, Carl F, Birkel L, Haskell WL. Increasing exercise among blue-collar employees: the tailoring of worksite programs to meet specific needs. Prev. Med. 1988; 17: 357-65.

21 Casperson CJ, DiPietro L. National estimates of physical activity among older adults. Med. Sci. Sports Exerc. 1991; 33: (Suppl.): S106.

22 Lewis CE, Raczynski JM, Heath GW, Levinson R, Hilyer JC Jr, Cutter GR. Promoting physical activity in African-American communities: the PARR project. Ethnicity Dis. 1993; 2 106-18.

23 Marcus BH, Dubbert PM, King AC, Pinto BM. Physical activity in women: current status and future directions. In: Stauton A, Gallent S, eds. Women's Health. Washington DC: American Psychological Association, 1995; 34979 .

24 Health Education Authority and Sports Council. Allied Dunbar National Fitness Survey-Main Findings. London: Sports Council and HEA, 1992.

25 Kearney M, Gibney MJ, Martinez JA, et al. Perceived need to alter eating habits among representative samples of adults from all member states of the European Union. Eur. J. Clin. Nutr. 1997; 51 (Suppl. 2): S30-5.

26 Brug J, VanAssema P, Kok GJ, Lenderink T, Glanz K. Selfrated dietary fat intake: association with objective assessment of fat, psychosocial factors and intention to change. J. Nutr. Educ. 1994; 26: 218-23.

27 Vaz de Almeida MD, Grąca P, Afonso C, D'Amicis A, Lappalainen R, Damkjaer S. Physical activity levels and body weight in a nationally representative sample in the European Union. Public Health Nutr. 1999; 2: 105-113.

28 Blair SN. How to assess habits and physical fitness. In: Matarazzo J, Weiss S, Herd J, Miller N, eds. Behavioural Health: a Handbook of Health Enhancement and Disease Prevention. New York: Wiley, 1984; 424-47.

29 Marcus BH, Sinkin LR. The stages of exercise behaviour. J. Sports Med. Phys. Fitness 1993; 33: 83-8. 
Appendix

\begin{tabular}{|c|c|c|c|c|c|c|c|c|}
\hline & \multicolumn{4}{|c|}{ Males (age in years) } & \multicolumn{4}{|c|}{ Females (age in years) } \\
\hline & All & $15-34$ & $35-54$ & $55+$ & All & $15-34$ & $35-54$ & $55+$ \\
\hline \multicolumn{9}{|c|}{ Precontemplation } \\
\hline Austria & 23 & 20 & 20 & 29 & 22 & 18 & 22 & 27 \\
\hline Belgium & 41 & 28 & 47 & 57 & 46 & 33 & 46 & 62 \\
\hline Denmark & 22 & 7 & 22 & 39 & 28 & 24 & 24 & 37 \\
\hline Finland & 21 & 15 & 24 & 26 & 14 & 11 & 12 & 22 \\
\hline France & 31 & 26 & 39 & 29 & 44 & 41 & 42 & 54 \\
\hline Germany & 29 & 21 & 27 & 41 & 35 & 27 & 37 & 40 \\
\hline Greece & 43 & 29 & 50 & 57 & 49 & 29 & 56 & 68 \\
\hline Ireland & 14 & 11 & 12 & 23 & 16 & 10 & 15 & 21 \\
\hline Italy & 12 & 8 & 11 & 18 & 19 & 12 & 25 & 27 \\
\hline Luxembourg & 29 & 28 & 30 & 31 & 30 & 17 & 32 & 40 \\
\hline Netherlands & 26 & 24 & 27 & 28 & 27 & 19 & 29 & 35 \\
\hline Portugal & 44 & 22 & 55 & 63 & 47 & 31 & 51 & 62 \\
\hline Spain & 30 & 15 & 35 & 44 & 35 & 24 & 36 & 46 \\
\hline Sweden & 20 & 14 & 20 & 31 & 20 & 12 & 18 & 33 \\
\hline UK & 15 & 9 & 13 & 26 & 20 & 14 & 16 & 32 \\
\hline \multicolumn{9}{|l|}{ Maintenance } \\
\hline Austria & 37 & 42 & 34 & 33 & 27 & 25 & 31 & 26 \\
\hline Belgium & 33 & 44 & 29 & 21 & 23 & 25 & 23 & 19 \\
\hline Denmark & 42 & 46 & 42 & 38 & 33 & 23 & 39 & 37 \\
\hline Finland & 27 & 30 & 22 & 30 & 24 & 22 & 27 & 23 \\
\hline France & 35 & 37 & 32 & 38 & 18 & 15 & 21 & 17 \\
\hline Germany & 32 & 38 & 30 & 29 & 19 & 22 & 17 & 18 \\
\hline Greece & 19 & 28 & 15 & 11 & 8 & 12 & 7 & 4 \\
\hline Ireland & 51 & 50 & 53 & 48 & 44 & 46 & 41 & 46 \\
\hline Italy & 44 & 48 & 36 & 49 & 35 & 35 & 36 & 32 \\
\hline Luxembourg & 33 & 35 & 28 & 36 & 24 & 31 & 24 & 15 \\
\hline Netherlands & 41 & 41 & 34 & 50 & 33 & 31 & 31 & 39 \\
\hline Portugal & 26 & 44 & 20 & 11 & 16 & 23 & 16 & 8 \\
\hline Spain & 30 & 39 & 24 & 24 & 20 & 25 & 25 & 11 \\
\hline Sweden & 38 & 42 & 32 & 39 & 31 & 25 & 35 & 33 \\
\hline UK & 46 & 46 & 46 & 41 & 34 & 33 & 37 & 30 \\
\hline
\end{tabular}

